\title{
Компенсация нелинейности сток-затворной вольт-амперной характеристики в полевых транзисторах с длиной затвора $\sim 100$ нм
}

\author{
() Е.А. Тарасова, С.В. Оболенский, С.В. Хазанова, Н.Н. Григорьева, О.Л. Голиков, А.Б. Иванов, А.С. Пузанов \\ Нижегородский государственный университет им. Н.И. Лобачевского, \\ 603600 Нижний Новгород, Россия \\ E-mail: tarasova@rf.unn.ru
}

Поступила в Редакцию 15 апреля 2020 г.

В окончательной редакции 21 апреля 2020 г.

Принята к публикации 21 апреля 2020 г.

Выполнен анализ нелинейности сток-затворных вольт-амперных характеристик в классических транзистоpax Шоттки и транзисторах с двумерным электронным газом на основе соединений AlGaAs/InGaAs/GaAs и InGaAs/GaAs. Проведен анализ влияния эффекта всплеска скорости носителей заряда в канале транзистора для различных профилей легирования исследуемых структур.

Ключевые слова: транзисторы Шоттки и НЕМТ, сток-затворная ВАХ, эффект всплеска скорости носителей заряда.

DOI: 10.21883/FTP.2020.09.49841.35

\section{1. Введение}

В современной наноэлектронике широко используются полевые транзисторы с каналом из слоя узкозонного полупроводника, формирующего квантовую яму, в которой образуется двумерный электронный газ (НЕМТ). Используются как структуры на основе соединений $\mathrm{AlGaAs} / \mathrm{InGaAs} / \mathrm{GaAs}$, InP/InGaAs/InP, GaAs/AlGaAs, InGaAs/GaAs, так и структуры на основе соединения GaN/AlGaN, в которых квантовая яма формируется за счет возникновения пьезоэлектрической поляризации на границах слоев $[1,2]$. Нелинейные искажения сигнала в усилителях на основе полевых транзисторов традиционно связывают с нелинейной сток-затворной вольт-амперной характеристикой $(\mathrm{BAX})[3]$. В данной работе проводится анализ нелинейности BAX полевых транзисторов с затвором Шоттки (ПТШ) на основе GaAs и $p$-HEMT на основе соединений $\mathrm{AlGaAs} / \mathrm{InGaAs} / \mathrm{GaAs}$ и InGaAs/GaAs. В настоящее время подобные соединения наиболее широко используются в производстве СВЧ НЕМТ. Особенностью транзисторов такого типа является то, что канал может состоять из нескольких слоев различной проводимости. Ранее авторами [4] детально изучались особенности физикотопологического моделирования данных структур, был предложен комплекс аналитических и численных моделей для расчета электрофизических параметров исследуемых приборов с малой погрешностью.

В работе [5] было изучено влияние различных профилей распределения легирующей примеси в канале классических транзисторов с затвором Шоттки (без квантовой ямы) на нелинейность сток-затворных вольтамперных характеристик. Рассматривалось равномерное распределение примесей в канале ПТШ и ступенчатое легирование, когда нижний слой легировался больше, чем верхний. Показано, что при равномерном распре- делении примесей, т.е. в первом случае, нелинейность сток-затворной ВАХ выше, чем в случае ступенчатого легирования (второй случай).

В современных НЕМТ, особенно с длинами канала $\sim 100 \mathrm{Hм}$, которые предназначены для работы на частотах 50-150 ГГц и выше, формирование транспорта электронов имеет целый ряд особенностей - квазибаллистический характер движения электронов вдоль канала, модуляция не только толщины, но и длины канала транзистора электрическим полем затвора, сильное влияние особенностей конструкции и технологии изготовления полупроводниковой гетероструктуры на нелинейные искажения усиливаемого сигнала. Данная работа посвящена моделированию указанных процессов и анализу их влияния на линейность сток-затворной характеристики.

\section{2. Общие положения}

Известно, что ток, протекающий в канале транзистора, зависит не только от концентрации электронов, но и от их скорости [6]. При реализации усиления в режиме „большого“ сигнала, за счет изменения размеров области пространственного заряда затвора Шоттки (при $\left.L_{g}<100 \mathrm{Hм}\right)$ наблюдается модуляция длины канала $L$ транзисторов в пределах от 150 до 300 нм (рис. 1). Причем с уменьшением длины затвора исследуемого транзистора становится более значительным соотношение максимального $\left(L_{3}\right)$ и минимального $\left(L_{1}\right)$ размеров области пространственного заряда в канале транзистора. Указанное отношение $L_{3} / L_{1}$ в короткоканальных приборах может составлять до 2-3 раз, другими словами, модуляция длины канала значительно влияет на эффекты, происходящие в канале как полевых транзисторов с затвором Шоттки, так и в НЕМТ. За счет квазибаллистических эффектов переноса электронов вдоль 
Таблица 1. Параметры сопоставляемых транзисторов

\begin{tabular}{|c|c|c|c|}
\hline & GaAs ПТШ & $\begin{array}{c}\mathrm{GaAs} / \mathrm{InGaAs} \\
\text { HEMT }\end{array}$ & $\begin{array}{c}\mathrm{AlGaAs} / \mathrm{InGaAs} / \mathrm{GaAs} \\
\text { HEMT }\end{array}$ \\
\hline $\begin{array}{l}\text { Затвор } \\
\text { Длина затвора } \\
\text { Подзатворный слой }\end{array}$ & $\begin{array}{c}\mathrm{Au} \\
100 \mathrm{HM} \\
\mathrm{GaAs}\end{array}$ & $\begin{array}{c}\mathrm{Au} \\
100 \mathrm{HM} \\
\mathrm{GaAs}\end{array}$ & $\begin{array}{c}\mathrm{Au} \\
100 \mathrm{HM} \\
\text { Широкозонный } \mathrm{AlGaAs}\end{array}$ \\
\hline \multirow{3}{*}{ Канал } & $N_{1}(\mathrm{GaAs})$ & $\delta$-слой 1 & $\delta$-слой 1 \\
\hline & \multirow{2}{*}{$N_{2}(\mathrm{GaAs})$} & Квантовая яма InGaAs & Квантовая яма InGaAs \\
\hline & & $\delta$-слой 2 & $\delta$-слой 2 \\
\hline $\begin{array}{l}\text { Изолирующий слой канал-подложка } \\
\text { Подложка }\end{array}$ & $\begin{array}{l}\text { GaAs } \\
\text { GaAs }\end{array}$ & $\begin{array}{l}\text { GaAs } \\
\text { GaAs }\end{array}$ & $\begin{array}{c}\text { Технологическая сверхрешетка } \\
\mathrm{GaAs}\end{array}$ \\
\hline
\end{tabular}

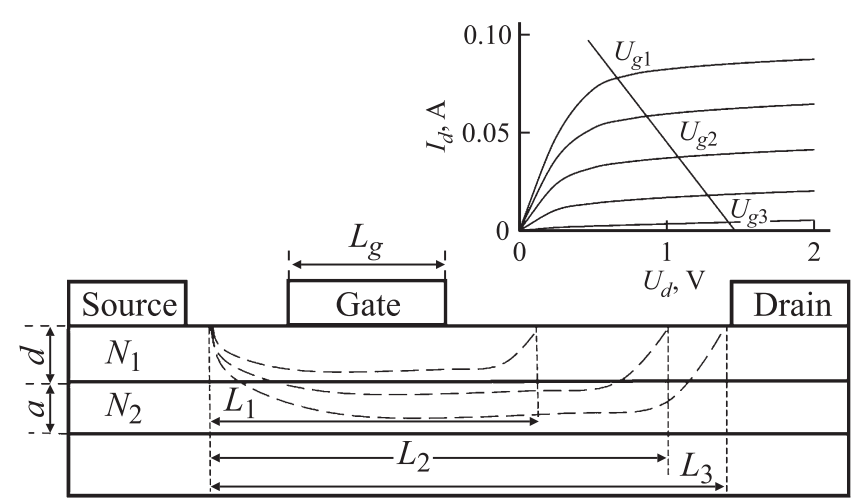

Рис. 1. Модель исследуемого транзистора. В случае классического ПТШ предполагалось, что слои толщиной $d$ и $a$ состоят из GaAs с концентрацией примесей $N_{1}$ и $N_{2}$ соответственно, а в случае НЕМТ второй слой представлял собой квантовую яму, в первом слое был размещен $\delta$-слой легирующей примеси. $L_{g}$ - длина затвора, $L_{k}$ - длина канала при соответствующих напряжениях на затворе $U_{g}$.

канала транзисторов средняя скорость носителей может в несколько раз меняться на каждом периоде колебаний усиливаемого сигнала. Все перечисленные факторы будут сильно сказываться на линейности сток-затворной BAX и искажениях сигнала. Кроме того, открытым оставался вопрос о влиянии различных полупроводниковых слоев, особенностей их легирования на нелинейность BAX исследуемых НЕМТ. Разработка методики, позволяющей проводить комплексную оценку влияния всех указанных эффектов на BAX HEMT, остается крайне актуальной.

\section{3. Объекты исследования}

В качестве основных объектов исследований были выбраны: полевой транзистор с затвором Шоттки, HEMT на основе соединений $\mathrm{AlGaAs} / \mathrm{InGaAs} / \mathrm{GaAs}$, и GaAs/InGaAs. Параметры исследуемых структур приведены в табл. 1. Для обеих НЕМТ структур рас- сматривалось два варианта конструкции - с одним $\delta$-слоем и с двумя, расположенными по обе стороны от квантовой ямы. При рабочих напряжениях в обоих типах транзисторов проводимость в $\delta$-слое отсутствовала.

В работе проводилось исследование влияния всплеска скорости в канале транзисторов с затвором Шоттки с однородным легированием (в данном случае предполагалось что $N_{1}=N_{2}$ ) и со ступенчатым легированием $\left(N_{1} \neq N_{2}\right)$ на крутизну ВАХ. Полученная в работе методика в дальнейшем применялась для анализа стокзатворных ВАХ современных НЕМТ с прямоугольной ямой.

\section{4. Математическая модель и методика расчетов}

Впервые самосогласованное численное моделирование уравнений Шредингера и Пуассона для расчетов пространственного распределения носителей заряда в канале транзисторов с высокой подвижностью электронов было проведено в работе [7]. Добавление уравнений непрерывности электрического тока и потоков энергии образуют диффузионно-дрейфовую и квазигидродинамическую модели переноса носителей заряда в квантоворазмерных структурах.

В настоящее время указанные системы уравнений реализованы в промышленных системах автоматизированного проектирования (САПР) изделий микро- и наноэлектроники, например, COMSOL Semiconductors [8], TCAD Silvaco [9] и TCAD Sentaurus [10]. При очевидных достоинствах указанных пакетов программ существует и ряд недостатков, связанных с особенностями численного решения систем дифференциальных уравнений в частных производных [11], всегда являющегося компромиссом между точностью и скоростью решения [12], а также существующей связью между погрешностью задаваемых параметров модели и получаемым конечным результатом моделирования. Анализ показывает [13-15], что в нелинейном режиме, необходимом 
при расчете интермодуляционных искажений, для получения точности выходных параметров в пределах 15\% необходимо определять наиболее критичные входные параметры с погрешностью не более $1 \%$, остальные входные параметры можно определять с погрешностью не более 10\%. Таким образом, для поисковых исследований оптимальным представляется следующий подход: расчет зонной диаграммы и распределение носителей заряда в канале транзистора с высокой подвижностью электронов осуществляется численно путем самосогласованного решения уравнений Шредингера и Пуассона; расчет всплеска скорости электронов в коротких структурах и дальнейший расчет стокзатворных вольт-амперных характеристик выполняются аналитически.

\section{1. Численная модель расчета параметров НЕМТ-структур}

В работе проводился расчет зонных диаграмм исследуемых структур и профилей распределения электронов путем решения одномерного уравнения Пуассона и совместного решения уравнения Пуассона и Шредингера в TCAD Silvaco. Кроме того, осуществлены расчеты зонных диаграмм и энергетических состояний в окрестности квантовой ямы с помощью оригинального численного метода. В основе данных численных расчетов лежит решение согласованных уравнений Шредингера и Пуассона, реализованное с помощью конечно-разностной схемы с учетом напряжения, приложенного в направлении роста структуры [16,17]. Хорошая корреляция результатов независимо проведенных расчетов (рис. 2) свидетельствует о корректности полученных данных. Одним из преимуществ оригинального численного расчета является возможность расчета зонных диаграмм

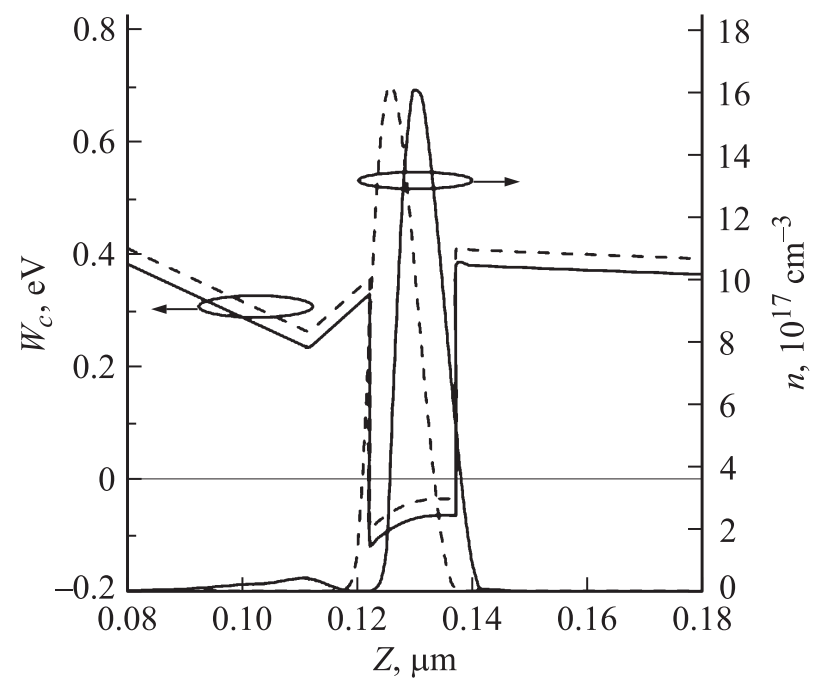

Рис. 2. Расчет зонной диаграммы и профиля распределения электронов структуры InGaAs/GaAs: пунктирная кривая расчет с использованием уравнения Пуассона и Шредингера TCAD Silvaco; сплошная кривая - оригинальная модель. и квантовой концентрации электронов в структурах с достаточно сложными профилями потенциала, в том числе с высоким уровнем неоднородного легирования, что проблематично сделать в САПР, предназначенных для расчета параметров типовых транзисторов. Одновременно с этим, данная модель численного расчета позволяет проследить тенденцию в изменении профиля концентрации при небольшом шаге по напряжению, приложенному к затвору. Кроме того, методика позволяет более плавное варьирование всех параметров, заложенных в исходной модели.

Предполагается, что расхождение максимумов концентрации носителей заряда в квантовой яме, полученных в разных расчетных моделях, также может быть связано с менее точной оценкой значения фонового легирования исследуемых структур, заложенной в модели расчета TCAD Silvaco.

На основе результатов рассчитанных зонных диаграмм и энергетического спектра в работе получены профили концентрации носителей в канале $\mathrm{AlGaAs} / \mathrm{InGaAs} / \mathrm{GaAs}$ и InGaAs/GaAs HEMT при различных напряжениях на затворе в открытом состоянии и вблизи отсечки. По полученным данным проведен аналитический расчет сток-затворных вольт-амперных характеристик, проанализирована крутизна полученных BAX.

\section{2. Аналитическая модель и методика расчетов}

Аналитически были рассчитаны вольт-амперные характеристики в классических GaAs-транзисторах с затвором Шоттки согласно модели, описанной в [3-5]. Рассматривались случаи однородного (для случая $N_{1}=N_{2}$ ) и ступенчатого (для различных значений $N_{1}$ и $N_{2}$ ) профиля распределения примесей. Расчет проводился как с учетом, так и без учета зависимости скорости носителей заряда в канале транзистора. Модель включала в себя выражения для расчета скорости носителей заряда в канале, толщины обедненного слоя и выражения для расчета плотности тока в канале транзистора.

Как указывалось выше, в коротких структурах средняя дрейфовая скорость носителей заряда может оказаться в несколько раз больше, чем их стационарная скорость, т.е. может быть реализован эффект всплеска скорости [6]. Зависимость максимально возможной дрейфовой скорости электронов в GaAs канале транзистора от длины канала считалась известной [6], в работе использована ее оригинальная аппроксимация (формула (1)).

Для аналитической оценки всплеска дрейфовой скорости в InGaAs канале исследуемых HEMT-структур использованы ранее полученные данные о зависимости времен релаксации энергии и импульса носителей заряда [18]. Таким образом, зависимость скорости носителей заряда в InGaAs от длины канала рассчитывалась по 
Таблица 2. Зависимость максимального тока стока в исследуемых НЕМТ от толщины спейсерного слоя

\begin{tabular}{c|c|c|c}
\hline \multirow{2}{*}{$\begin{array}{c}\text { Толщина } \\
\text { спейсерного } \\
\text { слоя, нм }\end{array}$} & $\begin{array}{c}\text { Толщина спейсерного слоя } \\
\text { (в долях от толщины } \\
\text { слоя квантовой ямы) }\end{array}$ & $\begin{array}{c}\mid c \\
I_{c}=\frac{I_{c}-I_{c_{0}}}{I_{c_{0}}} 100 \%\end{array}$ \\
\cline { 3 - 4 } & & HEMT $/ \mathrm{InGaAs}$ & $\mathrm{AlGaAs} / \mathrm{InGaAs} / \mathrm{GaAs}$ \\
4 & 0.13 & $-4 \%$ & $-10 \%$ \\
\hline 6 & 0.25 & $-15 \%$ & $-18 \%$ \\
\hline
\end{tabular}

Примечание. $I_{c_{0}}$ - максимальное значение тока стока при толщине спейсерного слоя, равной 1 нм; $I_{c}-$ максимальное значение тока стока при заданной толщине спейсерного слоя

формуле (2):

$$
\begin{gathered}
V_{s}=8.5 \cdot e^{-5 L} \cdot 10^{7} \mathrm{~cm} / \mathrm{c}, \\
V_{s}=7.5 \cdot e^{-0.03 L} \cdot 10^{7} \mathrm{~cm} / \mathrm{c},
\end{gathered}
$$

где $V_{s}$ - скорость электрона в канале транзистора, $L-$ длина канала с учетом ширины области пространственного заряда.

Описанные в работе методики расчета профилей потенциала и энергетических спектров позволили выявить влияние расстояния между $\delta$-Si легированным слоем и квантовой ямой (толщина спейсерного слоя), а также степени и характера легирования на нелинейность вольт-амперных характеристик НЕМТ.

\section{5. Результаты расчетов}

На первом этапе работы проводился анализ нелинейности характеристик ПТШ и проводилось сравнение результатов расчетов по предложенному в данной работе подходу с известными ранее данными [3,5] для верификации оригинальной методики расчета. На рис. 3 приведен расчет крутизны BAX для полевых транзисторов с затвором Шоттки как для однородного легирования, так и для ступенчатого с учетом и без учета эффекта всплеска дрейфовой скорости. Показано, что спад крутизны BAX сильнее выражен для транзисторов с однородным легированием. Кроме того, для каналов с обоими типами распределения примесей учет всплеска скорости носителей заряда в канале приводит к более резкому спаду крутизны характеристики, следовательно, данный эффект дает существенный вклад в нелинейные искажения усилителей на основе транзисторов с длинами затвора $<100$ нм и требует обязательного учета при проектировании современных приборов. Также был проведен расчет сток-затворной $\mathrm{BAX}$ полевого транзистора с затвором Шоттки с инвертированным легированием (в случае распределения примесей $N_{2}>N_{1}$ ). Получено, что выходные характеристики подобного типа транзисторов будут иметь максимальную линейность, как с учетом, так и без учета эффекта всплеска скорости носителей заряда в канале.

Полученные в результате расчетов данные о возможности реализации линейной сток-затворной ВАХ ПТШ

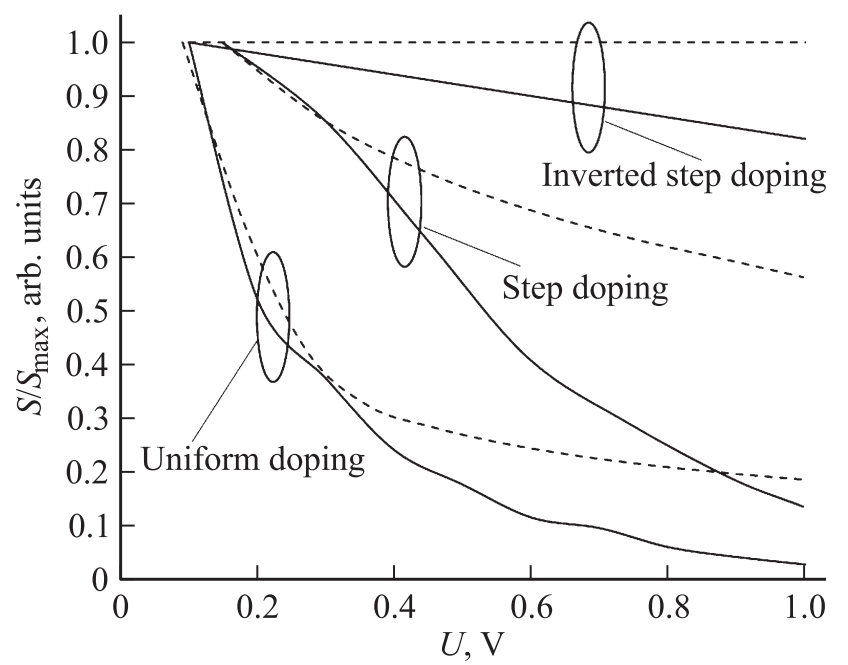

Рис. 3. Относительное изменение крутизны ПтШ для линейного легирования и легирования со ступенчатым профилем с учетом (сплошная кривая) и без учета (пунктирная кривая) зависимости скорости носителей заряда от длины канала.

за счет нелинейного (ступенчатого) профиля легирования коррелируют с данными [3,5], где исследовалась такая же задача, но без учета модуляции длины канала транзистора полем затвора. Это позволяет применить предложенную методику для анализа процессов в НЕМТ.

На втором этапе работы с использованием оригинальной верифицированной методики расчетов был проведен анализ зависимости сток-затворной ВАХ транзисторов на основе соединений $\mathrm{AlGaAs} / \mathrm{InGaAs}$ и $\mathrm{GaAs} / \mathrm{InGaAs}$ от толщины спейсерного слоя (расстояние между квантовой ямой и $\delta$-слоем) с использованием данных о распределении концентрации носителей заряда в квантовой яме исследуемых НЕМТ, полученных с помощью численных расчетов. Результаты расчетов представлены в табл. 2.

Получено, что максимальный ток стока $I_{c}$ и крутизна BAX в обоих типах структур будет иметь наибольшее значение при самой малой толщине спейсерного слоя. При этом транзисторы на гетероструктуре $\mathrm{AlGaAs} / \mathrm{InGaAs} / \mathrm{GaAs}$ оказываются более чувствительны к положению $\delta$-слоя относительно квантовой ямы. При достижении толщины спейсерного слоя порядка поло- 


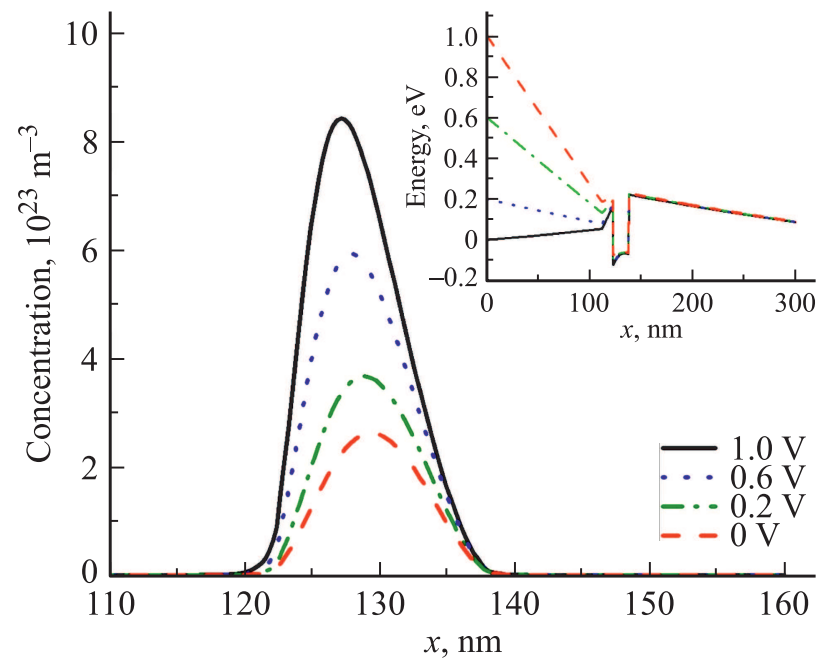

Рис. 4. Расчет профиля распределения электронов для InGaAs-структуры с одним $\delta$-легирующим слоем. На вставке расчет зонной диаграммы структуры для различных напряжений на затворе.

вины толщины квантовой ямы (5-7 нм) выходная мощность исследуемых полевых транзисторов уменьшится в 1.5-2 раза. Таким образом, толщину спейсерного слоя проектируемых приборов необходимо подбирать с учетом особенностей зависимости подвижности и дрейфовой скорости носителей заряда в канале, которые в свою очередь существенно зависят от взаимного положения $\delta$-легированного слоя и квантовой ямы [19].

Далее была проведена сравнительная оценка влияния характера легирования на крутизну сток-затворной вольт-амперной характеристики. С этой целью были исследованы структуры с двумя $\delta$-легирующими слоями, расположенными по обе стороны от квантовой ямы. В работе рассматривались как структуры с одинаковой степенью легирования $\delta$-слоев, так и случай инвертированного легирования, когда слой, находящийся ниже квантовой ямы $(\delta$-слой 2$)$, легирован больше. Расчеты зонной диаграммы и профиля распределения электронов исследуемой структуры с одним $\delta$-слоем приведены на рис. 4 , с двумя $\delta$-слоями - на рис. 5 . Данные численных расчетов показывают, что двустороннее $\delta$-легирование приводит к тому, что профиль концентрации носителей проводящего канала с ростом напряжения становится более симметричным по сравнению с односторонним легированием. Указанный эффект приводит к изменению интегральной концентрации носителей заряда в канале и к увеличению крутизны ВАХ транзистора на исследуемой структуре на 10\%. Также рассматривался случай, когда $\delta$-слой 2 легировался в несколько раз больше, чем слой, находящийся над квантовой ямой $(\delta$-слой 1$)$, после чего анализировалась зависимость стокзатворной характеристики от положения $\delta$-слоя 1 относительно квантовой ямы. По результатам расчетов можно сделать вывод, что инвертированное легирование $\delta$-слоев позволяет получить линейную сток-затворную BAX транзистора без учета эффекта всплеска скорости и уменьшить влияние указанного эффекта на нелинейные искажения.

Затем была аналитически рассчитана сток-затворная BAХ НЕМТ структуры (рис. 6) со ступенчатым „инвертированным“ легированием. Предполагалось, что слой в канале, прилегающий к буферу $\left(N_{2}\right)$, легирован сильнее (в 10 раз), чем слой канала, прилегающий к затвору транзистора. Подобное распределение примесей в подзатворной области транзистора может полностью компенсировать нелинейность ВАХ, возникающую из-за влияния всплеска скорости носителей заряда в канале

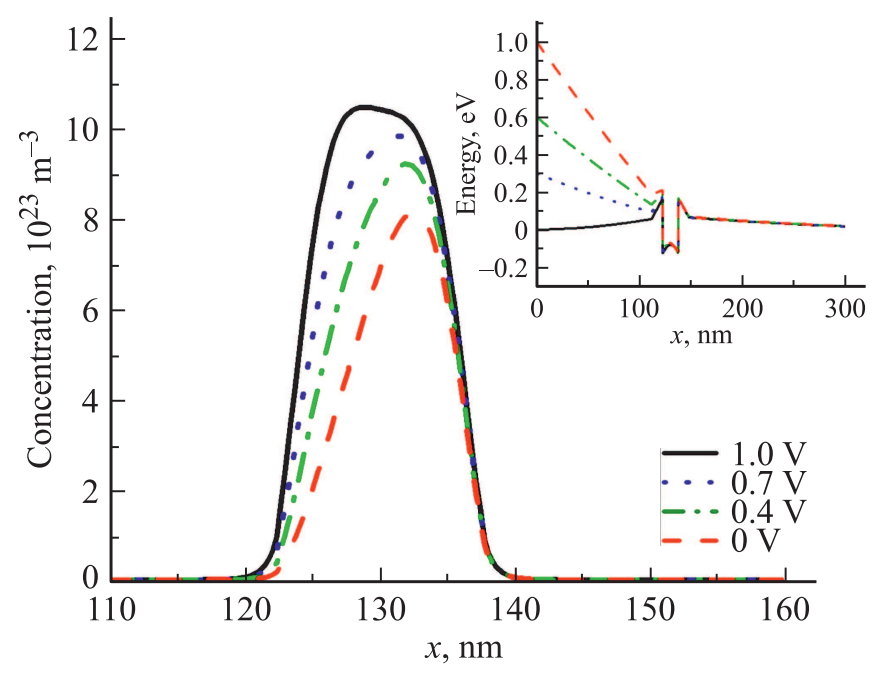

Рис. 5. Расчет профиля распределения электронов для InGaAs-структуры с двумя $\delta$-легирующими слоями. На вставке - расчет зонной диаграммы структуры для различных напряжений на затворе.

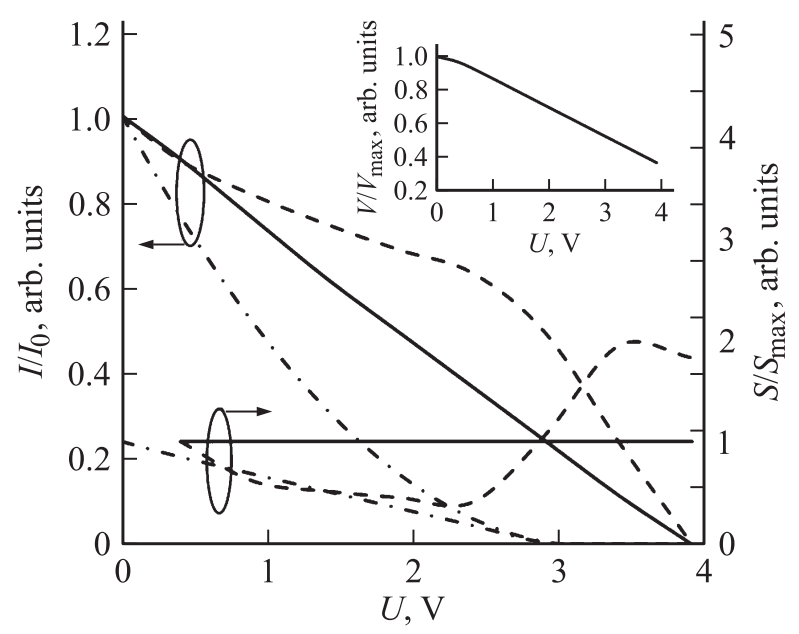

Рис. 6. Компенсация нелинейности ВАХ за счет изменения профиля легирования в НЕМТ: 1 - расчет ВАХ с учетом изменения всплеска скорости в канале транзистора, 2 расчет BAX для инвертированного легирования без учета всплеска скорости в канале транзистора, 3 - расчет ВАХ для классического ступенчатого легирования. 
транзистора. Сплошной линией на рис. 6 показана рассчитанная сток-затворная ВАХ и ее крутизна с учетом изменения скорости на 60\% (величина изменения скорости носителей заряда в канале НЕМТ показана на вставке к рис. 6).

\section{6. Заключение}

В работе предложена теоретическая методика анализа влияния параметров гетероструктур на линейность стокзатворных характеристик полевых транзисторов с затвором Шоттки и НЕМТ, которая позволяет оценить степень влияния как профиля распределения примесей, так и эффекта всплеска скорости носителей заряда в канале НЕМТ на линейность сток-затворных ВАХ. С одной стороны, данный подход позволяет оценивать влияние каждого из приведенных эффектов на линейность ВАХ, a c другой - оптимизировать конструкцию НЕМТ с целью компенсации нелинейности ВАХ, вызванной всплеском скорости в канале.

Таким образом, можно заключить, что при проектировании усилителей на основе современных НЕМТ с длинами каналов 100-200 нм необходимо учитывать не только поперечные изменения концентрации носителей заряда в канале, но и продольные, связанные с эффектом всплеска скорости в канале транзистора. Компенсацию всплеска скорости предлагается проводить с помощью увеличения легирования слоя канала, прилегающего к буферу в полевых транзисторах с затвором Шоттки, и с помощью добавления второго легирующего $\delta$-слоя в перспективных HEMT на основе GaAs.

\section{Финансирование работы}

Работа поддержана грантом Министерства науки и высшего образования РФ, полученным в рамках ФЦП „Исследования и разработки по приоритетным направлениям развития научно-технологического комплекса России на 2014-2020 годы“. Уникальный идентификатор проекта RFMEFI62020X0003. Номер соглашения 07515-2020-529.

\section{Конфликт интересов}

Авторы заявляют, что у них нет конфликта интересов.

\section{Список литературы}

[1] В.Г. Тихомиров, В.Е. Земляков, В.В. Волков, Я.М. Парнес, В.Н. Вьюгинов, В.В. Лундин, А.В. Сахаров, Е.Е. Заварин, А.Ф. Цацульников, Н.А. Черкашин, М.Н. Мизеров, В.М. Устинов. ФТП, 50 (2), 245 (2016).

[2] Е.А. Тарасова, С.В. Оболенский, О.Е. Галкин, А.В. Хананова, А.Б. Макаров. ФТП, 51 (11), 1543 (2017).

[3] С. Зи. Физика полупроводниковых приборов (М., Мир, 1984).
[4] Е. А. Тарасова, Д.С. Демидова, С.В. Оболенский и др. ФТП, 46 (12), 1587 (2012).

[5] R.E. Williams, D.W. Shaw. IEEE Trans. Electron Dev., ED-25, 600 (1978).

[6] Ю. Пожела. Физика быстродействующих транзисторов (Вильнюс, Мокслас, 1989).

[7] K. Yokoyama, K. Hess. Phys. Rev. B, 33 (8), 5595 (1986).

[8] Электронный pecypc https://www.comsol.com/

[9] Электронный pecypc https://www.silvaco.com/

[10] Электронный pecypc https://www.synopsys.com/

[11] D. Vasileska, S.M. Goodnick, G. Klimeck. Computational electronics. Semiclassical and quantum device modeling and simulation (N.Y., CPC Press Taylor \& Francis Group).

[12] Р. Хокни, Дж. Иствуд. Численное моделирование методом частии, (М., Мир, 1987).

[13] Ю.В. Королев, И.А. Ющенко. В сб.: Диэлектрики и проводники (Киев, Высш. шк., 1978) вып. 14, с. 102.

[14] Д. Калахан. Методы машинного расчета электронных схем (М., Мир, 1970).

[15] Ю.Р. Носов, К.О. Петросянц, В.А. Шилин. Математические модели элементов интегральной электроники (М., Сов. радио, 1976).

[16] С.В. Хазанова, В.Е. Дегтярев, С.В. Тихов, Н.В. Байдусь. ФТП, 49 (1), 53 (2015).

[17] С.В. Хазанова, В.Е. Дегтярев, Н.Н. Григорьева, О.Л. Голиков. Физические и физико-химические основы ионной имплантации (РИУ ННГУ им. Н.И. Лобачевского, 2018) c. 33 .

[18] И.Ю. Забавичев, Е.С. Оболенская, А.А. Потехин, А.С. Пузанов, С.В. Оболенский, В.А. Козлов. ФТП, 51 (11), 1489 (2017).

[19] М. Шур. Современные приборы на основе арсенида галлия (М., Мир, 1991).

Редактор А.Н. Смирнов

\section{The compensation of nonlinearity drain-gate $I-V$ characteristics in field effect transistors with a gate length $\sim 100$ nanometers}

\author{
E.A. Tarasova, S.V. Obolensky, C.V. Khazanova, \\ N.N. Grigoryeva, O.L. Golikov, A.B. Ivanov \\ Lobachevsky State University \\ of Nizhny Novgorod, \\ 603950 Nizhny Novgorod, Russia
}

Abstract The paper is devoted to the analysis of the nonlinearity of the drain-gate $I-V$ characteristics in classical Schottky transistors and transistors with two-dimensional electron gas based on AlGaAs/InGaAs /GaAs and InGaAs/GaAs compounds. The effect of the increase of the velocity of charge carriers in the transistor channel for various doping profiles of the structures was analyzed. 